\title{
The Homework Shared by the Team in Vocational Training
}

\author{
Kai Xue ${ }^{1, a}$, Shouchen $\mathrm{Xu}^{2, \mathrm{~b}}$, Xilin Zhang ${ }^{3, \mathrm{c}}$, Xiaojuan Han ${ }^{4, \mathrm{~d}}$ \\ ${ }^{1}$ State Grid Jilin Electric Power Company Limited Training Center, Changchun, Jilin 130022, China; \\ ${ }^{2}$ State Grid College of Management, Beijing, 100085, China; \\ ${ }^{3}$ State Grid Jilin Electric Power Company Limited Changchun Power Supply Company, Changchun, \\ Jilin 130021, China; \\ ${ }^{4}$ Department of Control and Computer Engineering University of North China Electric Power, Beijing, \\ 102206, China.

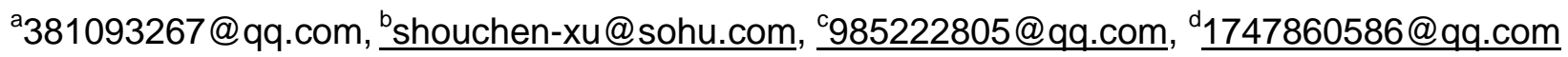

Keywords: Homework, employees, vocational training.

\begin{abstract}
In order to enhance the effectiveness of on-the-job training, and hone the communication and coordination skills of trainees while improving their professional and technical skills. This paper discusses the significance of homework sharing in vocational training, the principles of task selection, the structure of teams in such training sessions, the control of training progress, and the design of specific cases. Homework sharing in vocational training gives full play to the trainees' learning initiative and creativity, expands the depth and breadth of their skills, and helps improve their technical skills, team spirit and ability to cooperate for different tasks.
\end{abstract}

\section{Introduction}

To keep our practices abreast with the time, we need to study the laws underlying vocational training continuously ${ }^{[1,2,3,4,5]}$.

Vocational training usually comprises of several parts: preview, teaching, homework, practical training, review and test; and homework is an important part.

Homework assigned to individual trainees, and a major of homework, can foster their ability to complete a task independently and systematically and plays an essential role in fostering the trainees' ability to identify, analyze and solve problems independently.

However, in the workplace today, many projects need to be completed by a team through close cooperation. Some parts of a project may go in parallel, while others can only be started when prior tasks are completed and the number of such prior tasks can be $1 \sim \mathrm{N}$. Therefore, communication and coordination skills, team spirit, and the ability to cooperate with others are what is urgently needed in today's workplace and constitute an important part of vocational training.

\section{Significance of Homework Sharing in Vocational Training}

When homework is assigned to a team of trainees who are to share the workload, team members will value the honor of the team as a whole and make more efforts to fulfill their task. In this process, team members will give full play to their enthusiasm, initiative and creativity to learn and to improve their knowledge and skills, and cooperate with other members effectively and efficiently to achieve their shared goal. Better communication and coordination among team members can create favorable conditions for all members and foster their ability to communicate and coordinate with $1 \sim \mathrm{N}$ other related members. Discussions among team members may inspire people to come up 
with more solutions to a problem, promoting creative thinking. Mutual help among team members builds understanding and friendship and lays a good foundation for cooperation at work in the future. Therefore, homework sharing is an important form of all-round training for team members during vocational training.

\section{Task Selection for Homework Sharing}

3.1 A homework assignment can be divided into several relatively independent tasks. Homework sharing should be arranged for assignments that can be easily divided to several relatively independent tasks. This is the basis for the homework to be shared by team members. A homework assignment that cannot be divided should not be split forcibly. For example, a homework assignment related to automatic distribution at a substation can be divided by the level of the substation system, e.g. the station level, bay level and process level.

3.2 between tasks should be clear-cut. Clear-cut divisions between tasks allow team members to have a clear idea of what they each are responsible for, with no ambiguity. Thus, they will know work to focus on.

3.3 Tasks should be connected. Different tasks of a homework assignment should be connected horizontally or vertically. It should be necessary for each team member to communicate and coordinate with one or more other member(s) to complete their own task. The closer the connection between tasks is, the more effective the homework will likely be for enhancing cooperation.

3.4 Frequency of homework sharing. Each training course for first-line personnel should contain one homework assignment to be shared. In training courses for team leaders, technicians and managers there can be more such assignments, maybe two or three.

3.5 Workload of shared homework. The total workload of a homework assignment to be share and the workload for each team member should be determined according to the duration of the training course. The workload may be heavier for longer courses and lighter for shorter ones. The workload, in principle, should be shared equally between team members and suitable for trainees with average technical skills to complete without much too much difficulty.

\section{Team Structure for Homework Sharing}

Each team may have 4-6 members. Smaller teams may not be effective in improving the communication and coordination skills, while larger teams may be hard to manage.

Teams should be reasonably structured. For homework assignments requiring great creativity, a team may preferably have members with varied technical levels, with a capable and sociable person in the charge. Such a structure will enable the team leader and other more capable members in the team of help others improve. For assignments targeted at reviewing previous courses, team members should preferably have similar technical levels so that no one on the team needs to worry about not being able to complete the task.

\section{Progress Control for the Homework Sharing}

The instructors should keep track of how well each team is doing, offer help to individual teams when necessary, especially by showing the way forward to teams that lag behind, so as to ensure that all the teams are able to complete the assignment on schedule.

\section{Case Design for the Homework Sharing}


6.1 Overview of remote online monitoring system for power cable fire safety ${ }^{[6,7]}$

In order to meet power demands, the power supply cables are taking up an increasing proportion in the urban power grid, which results in more and more workload in the operation, management, testing and maintenance of the power supply cables. With the rapid development of urban construction, power demands are increasing, and power grid load will keep increasing and connect more equipment and systems. Such factors as cable construction and cable joint quality have all increased the risk of cable operation.

Because the construction quality of cable joints is poor or the constructers are not familiar with the construction process of prefabricated cable fittings, cable joints may become overheated under long-time heavy-current (overload) operating conditions, and result in accidents. In a mild case, this may cause long power failure to users. In a serious case, this may cause chain reactions and thus breakdown of the peripheral equipment of cable lines, or even partial or substantial breakdown of the power distribution system, which seriously affects the safe and reliable operation of the electric power system, and leads to huge economic losses. Statistics show that cable joint accidents take up $90 \%$ of the total cable accidents. Cable joints have become one of the vulnerable spots in the safe operation of a power supply cable network.

The project is mainly about the remote online monitoring of the temperature and load changes of $66 \mathrm{kV}$ overhead cables, $10 \mathrm{kV}$ underground cables, and cables in coupling boxes and RMUs of a power distribution system. The system combines on-site real-time data collection and theoretical load calculation to obtain real-time and non-real-time data via GPRS. It keeps track of the temperature changes and the load changes at monitored points to provide early warning and off-limit alarm for status, preventing fire risks and ensure safe operation of the city power grid.

The remote online monitoring system of power cable fire safety consists of communications, power, wireless temperature sensor, monitoring the terminal data acquisition repeaters and host computer. This article discusses the design and implementation of power supply, wireless temperature sensor, monitoring terminal and data acquisition repeaters.

6.1.1 Design of wireless temperature sensor. The sensor is of ultra-low power consumption. It adopts the wireless radio frequency communication technology and an anti-interference design for the hardware and software in high voltage electric fields. Its power supply is designed for a service life of 7 to 8 years. The sensor collects temperature data and transmits it wirelessly from the monitored points.

6.1.2 Design of data collection management terminal. The terminal receives data from monitored points wirelessly. It adopts industry bus and GSM/GPRS wireless communication to transmit data to remote computer master station system.

6.1.3 Terminal power supply system. For power supply systems above $10 \mathrm{kV}$, the power supply unit is of great importance. In this case, solar power supply is adopted for $66 \mathrm{kV}$ overhead cables and mutual inductance is adopted for $10 \mathrm{kV}$ underground cables. For both of the two categories of cables, hybrid energy storage of super capacitor and battery is used to solve the technical problems of instantaneous strong current in communication and ensure power supply for the normal operation of the system.

6.1.4 Master station system for remote data management. The system monitors data from each point in real time and records the temperature changes and the load current changes to provide early warning and off-limit alarm for cable status. It also allows you to retrieve historical data and form report sheets, giving early warnings for fire hazards.

Online monitoring of the temperatures of coupling boxes and cable joints can prevent temperature increases caused by loosening, poor contacts and long-term overload of the joints, and thus avoiding 
losses caused by fire and other major accidents and ensuring safe power grid operation.

6.1.5 System communication.High-voltage cable distribution boxex located in every corner of the street,courtyard city,distributed widely with large number.To monitoring the cable connector,need the help of cover a wide range of reliable communication network.

6.2 Task division for developing a remote online monitoring system for power cable fire safety. Team member 1: Design a wireless temperature sensor.

Team member 2: Design the hardware and software for data collection management terminal.

Team member 3: Design the terminal power supply system.

Team member 4: Design the hardware and software for remote data management master station system.

Team member 5: Team leader and technical head in charge of overall coordination; do the programming of the protocol software for the communication between the sensor and the data collection management terminal, and between the data collection management terminal and the remote data management master station system.

Schedule: 16 weeks.

\section{Conclusions}

Homework sharing in vocational training can give full play to the trainees' learning initiative and creativity, expand the depth and breadth of their skills, and play a very good role in fostering their techniques, team spirit, and ability to cooperate for different tasks.

\section{References}

[1] Zhang Xilin, Xu Shouchen, Design on the Curriculum Reform for Experimental Classes of Secondary Majors in Electric Power System [C] 2nd International Conference on Management Science and Industrial Engineering, 2013, pp.506-509.

[2] Zhang Xilin, Xu Shouchen, Wang Shuo. On the Comprehensive Quality and Personality Charm of Technical Innovation Leaders [J] China Power Human Resources, vol. 9, pp.37-39, 2011.

[3] Zhang Xilin, Yang Guiying, Liu Xiaowei. Training Management Experience of Power Dispatching Department of Power Supply Enterprises [J]. China Electric Power Education, vol. 29, pp.48-50, 2010.

[4] Li Yiling, Zhang Xilin, Zhang Yan. Originality, Question Bank Construction and Practice of "Five-One" Theme Training [J]. China Electric Power Education, vol. 27, pp.229-231, 2010.

[5] Zhang Xilin, Wang Shuo, Li Linze. Be an Lv Qingsen-type Electric Power Worker [J]. China Power Human Resources, vol. 3, pp.80-82, 2012.

[6] Xilin Zhang,Zhenhao Wang, Yechun Xin, Subsystem design and development of remote online monitoring system for power cable fire safety in Changchun power grid [C]2012 2nd International Conference Applied Robotics for the Power Industry, 2012, pp.112-115.

[7] Xilin Zhang,Zhenhao Wang, Yechun Xin, Overall design of Changchun grid power cables fireproof remote online monitoring system[C]2012 2nd International Conference Applied Robotics for the Power Industry, 2012, pp.105-108. 